Quim. Nova, Vol. 35, No. 2, 416-419, 2012

\title{
INVESTIGANDO CINZA DA CASCA DO ARROZ COMO FASE ESTACIONÁRIA EM CROMATOGRAFIA: UMA PROPOSTA DE AULA EXPERIMENTAL NOS CURSOS DE GRADUAÇÃO
}

\author{
João R. de Freitas Filho*, Jucleiton J. Rufino de Freitas e Ladjane Pereira da Silva \\ Departamento de Química, Universidade Federal de Rural de Pernambuco, Av. Dom Manoel de Medeiros, s/n, 52171-900 Recife \\ - PE, Brasil \\ Juliano C. Rufino Freitas \\ Departamento de Química Fundamental, Universidade Federal de Pernambuco, 50740-540 Recife - PE, Brasil
}

Recebido em 12/3/11; aceito em 21/8/11; publicado na web em 30/9/11

\begin{abstract}
THE INVESTIGATION RICE HUSK ASH AS A STATIONARY PHASE IN CHROMATOGRAPHY: A PROPOSAL OF EXPERIMENTAL CLASS IN UNDERGRADUATE COURSES. This article describes an experiment that involves the extraction and separation of the pigments of spinach extract by column chromatography using the silica obtained from rice husk ash as a stationary phase. The experimental procedure is very simple to apply in the chemistry laboratory, and allowed to illustrate some concepts of organic chemistry: structure of organic molecules, solubility, polarity, extraction, partition coefficient, adsorption and retention factor $\left(\mathrm{R}_{\mathrm{f}}\right)$, as well as objectives and fundamentals of chromatographic methods. The experiment can be carried out in a $4 \mathrm{~h}$ period.
\end{abstract}

Keywords: rice husk ash; stationary phase; chromatography.

\section{INTRODUÇÃO}

A cromatografia é uma técnica utilizada para separação dos componentes de uma mistura, na qual os componentes a serem separados distribuem-se em duas fases: estacionária e móvel. ${ }^{1}$ A fase estacionária pode ser um sólido ou um líquido disposto sobre um suporte sólido com grande área superficial. A fase móvel, que pode ser gasosa, líquida ou ainda um fluido supercrítico, passa sobre a fase estacionária, arrastando consigo os diversos componentes da mistura. É uma técnica de separação especialmente adequada para ilustrar os conceitos de interações intermoleculares, polaridade e propriedades de funções orgânicas, com uma abordagem ilustrativa e relevante, segundo da Silva et al.. ${ }^{2}$

A cromatografia pode ser utilizada para a identificação de compostos por comparação com padrões previamente existentes, para a purificação de compostos, separando-se as substâncias indesejáveis e para a separação dos componentes de uma mistura. ${ }^{3}$ Existem diferentes formas de cromatografia: em coluna, planar (cromatografia em papel, a cromatografia por centrifugação e a cromatografia em camada delgada), gasosa, líquida (que pode ser cromatografia líquida clássica - CLC e cromatografia líquida de alta eficiência - CLAE) e a supercrítica (CSC). Neste trabalho, dar-se-á destaque à cromatografia em coluna e cromatografia em camada delgada (CCD).

A CCD é uma técnica de adsorção líquido-sólido. Nesse caso, a separação se dá pela diferença de afinidade dos componentes de uma mistura pela fase estacionária. O parâmetro mais importante a ser considerado em CCD é o fator de retenção $\left(\mathrm{R}_{\mathrm{f}}\right)$, que é a razão entre a distância percorrida pela substância em questão e a distância percorrida pela fase móvel. Já a cromatografia em coluna é uma técnica muito utilizada para isolamento de produtos naturais e purificação de produtos de reações químicas. A principal etapa ao se utilizar essa técnica é o empacotamento, o qual, entre outros fatores, definirá a eficiência da separação. A gel de sílica ${ }^{4-11}$ é a fase estacionária mais utilizada, sendo seguida pela alumina, ${ }^{5-7}$ tanto na cromatografia em camada delgada quanto na cromatografia em coluna.

Por outro lado, diversos experimentos envolvendo ensaios cromatográficos são descritos na literatura usando como fase estacionária

\footnotetext{
*e-mail: joaoveronice@yahoo.com.br
}

giz, ${ }^{12}$ mistura de areia e mármore, ${ }^{13}$ açúcar comercial,,${ }^{14}$ amido, carbonato de cálcio para analisar princípios ativos de medicamentos, ${ }^{5}$ extrato de folhas de espinafre,,${ }^{7,9,12}$ tinta de caneta, ${ }^{12,14}$ extrato de flores, ${ }^{15}$ pigmento de pimentões, ${ }^{16}$ entre outros.

Mediante o exposto, propõe-se a utilização da sílica obtida da cinza da casca do arroz como fase estacionária.

\section{Sílica obtida da cinza da casca do arroz}

A casca do arroz é um material fibroso, composto basicamente por celulose, lignina e matéria orgânica. A principal utilização desse rejeito é na geração de energia térmica, entretanto desse uso é gerado um resíduo negro, de difícil degradação e com alto teor de silício que, se depositado de maneira incorreta, pode causar danos ao meio ambiente e aos seres humanos. ${ }^{17}$

Durante o processo de beneficiamento do arroz, resulta como subproduto a casca de arroz, que representa cerca de $23 \%$ do peso do arroz. Esta casca, devido a sua alta dureza, fibrosidade e natureza abrasiva, leva à obtenção de produtos de baixa propriedade nutritiva, boa resistência ao desgaste e muita cinza. ${ }^{18}$ Atualmente, parte desta casca está sendo utilizada na fabricação de blocos e painéis empregados na construção civil, onde substitui a fibra de madeira comumente utilizada. ${ }^{19}$ Uma grande quantidade desta casca é reaproveitada dentro da própria usina de beneficiamento de arroz onde, a partir da sua combustão, é gerado calor para a parboilização dos grãos. Como resíduo desta combustão, é produzida a cinza de casca de arroz. Esta cinza, até então útil somente para estabilização de solos (ainda sem comprovação técnica) e aterros sanitários, devido ao seu elevado teor de óxido de silício, está sendo utilizada, segundo Fonseca, ${ }^{18}$ na fabricação de vidros, isolantes térmicos, tijolos prensados e materiais refratários, bem como na produção de cimento portland e, na forma de agregado, em argamassas e concretos. ${ }^{19}$

Se a cinza da casca do arroz for aquecida para eliminar o carbono residual, pode-se obter aproximadamente $95 \%$ de sílica pura $\left(\mathrm{SiO}_{2}\right)$. Este processo é relativamente simples, barato e pode vir a substituir a sílica gel comercializada a custo alto. Por outro lado, se essa cinza for descartada no meio ambiente provocará poluição, pois se sabe que a cinza gerada na combustão apresenta certa quantidade de carbono 
residual, que é um grave poluente para o solo. Fica evidente que seu aproveitamento adequado resultará em benefício ao processo de conservação ambiental.

Diante do exposto, neste trabalho propõe-se a utilização da sílica obtida da cinza da casca do arroz (após tratamento para eliminação do carbono residual e outros materiais orgânicos e inorgânicos) como fase estacionária para separação dos diferentes pigmentos presentes nos extratos de espinafre fresco. Utilizou-se a sílica obtida da cinza da casca do arroz, pois realizar experimentos de cromatografia em aula experimental, em turmas de graduação, apresenta uma série de dificuldades, como o alto custo da sílica gel.

\section{PARTE EXPERIMENTAL}

\section{Materiais e reagentes}

Foram utilizadas colunas cromatográficas de $25 \mathrm{~mL}$, folhas de espinafre, éter de petróleo, etanol, erlenmeyer de $50 \mathrm{~mL}$, béquer de $50 \mathrm{~mL}$, béquer de $400 \mathrm{~mL}$, algodão, papel de filtro, chapa de aquecimento, funil de vidro com haste, suporte universal, garra para coluna, pipeta de Pasteur, vidro de relógio de $4 \mathrm{~cm}$ de diâmetro, proveta, gral com pistilo, ácido clorídrico, água destilada, cuba cromatográfica, tubo de ensaio, mufla, capilares, balança, cinzas de casca do arroz e sulfato de sódio anidro.

\section{Procedimentos experimentais}

\section{Parte 1 - Preparação do suporte para fase estacionária}

Coloque $100 \mathrm{~g}$ de cinza da casca do arroz em uma cápsula de porcelana e aqueça em mufla a uma temperatura de $700^{\circ} \mathrm{C}$ por $18 \mathrm{~h}$. Lave o produto obtido até que a água de lavagem saia limpa. Coloque o produto obtido em um béquer de $400 \mathrm{~mL}$ e adicione o ácido clorídrico até que todo o produto seja coberto. Deixe em repouso com o béquer coberto por pelo menos um dia. Lave o produto até que todo o ácido seja eliminado e deixe secar em estufa a $120^{\circ} \mathrm{C}$. Depois de seca a sílica, passe-a pela peneira.

\section{Parte 2 - Preparação das amostras}

Pese uma amostra de espinafre, em torno de 3,0 g da folha, e macere com 3,0 g de sílica e 4,0 g de sulfato de sódio anidro. A seguir, adicione $10 \mathrm{~mL}$ de etanol e $20 \mathrm{~mL}$ de éter de petróleo para a extração dos pigmentos, deixando a mistura em repouso por $10 \mathrm{~min}$. Filtre o produto resultante e depois concentre a amostra até um volume de 5 $\mathrm{mL}$ com aquecimento em chapa a $70^{\circ} \mathrm{C}$.

\section{Parte 3 - Cromatografia em camada delgada (CCD)}

Duas gotas do concentrado obtido da extração dos pigmentos de espinafre foram aplicadas, em pontos diferentes, em uma placa cromatográfica de sílica gel com dimensões de 2,5 x 7,5 cm, desenvolvidas em uma cuba contendo a mistura de solventes hexano:etanol (9:1).

\section{Parte 4 - Purificação por cromatografia de coluna (CC)}

A montagem da coluna cromatográfica foi feita segundo descrito na literatura. ${ }^{20}$ Parte do concentrado obtido da extração dos pigmentos de espinafre foi submetido à cromatografia em coluna (CC) usando sílica obtida da casca do arroz e eluída inicialmente com éter de petróleo e, em seguida, com éter de petróleo-etanol (9:1), éter de petróleo-etanol (6:4) e, finalmente, apenas etanol.

\section{RESULTADOS E DISCUSSÃO}

A sílica usada no empacotamento da coluna foi obtida da cinza da casca do arroz após tratamento de aquecimento para retirada do carbono residual e lavagem com ácido para eliminação de outros constituintes orgânicos e inorgânicos. A Figura 1 mostra o antes e o depois do tratamento da cinza da casca de arroz. Este procedimento experimental antecedeu o período de $4 \mathrm{~h}$, destinado à extração de pigmentos, realização da cromatografia em camada delgada, empacotamento e realização da separação cromatográfica dos constituintes do espinafre.

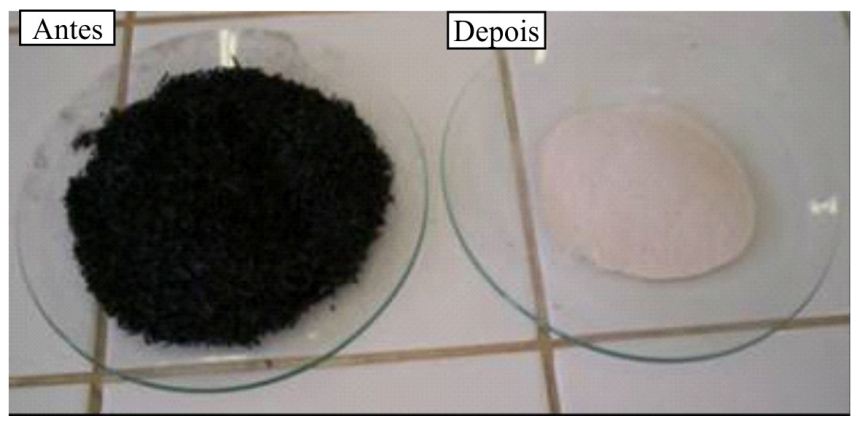

Figura 1. Sílica obtida da cinza da casca do arroz após $18 \mathrm{~h}$ de aquecimento em mufla a uma temperatura de $700{ }^{\circ} \mathrm{C}$ e lavagem com ácido clorídrico e água destilada

O extrato de pigmentos de espinafre foi obtido por maceração com éter de petróleo e um pouco de etanol. A fase aquosa, contendo etanol, foi separada e a fase extrato/éter de petróleo foi "secada" com sulfato de sódio anidro durante alguns minutos e aplicada em dois pontos em uma placa analítica (CCD). Os experimentos de cromatografia em camada delgada indicaram o sistema hexano - etanol (9:1) como o eluente para corrida e separação dos produtos, conforme a Figura 2.

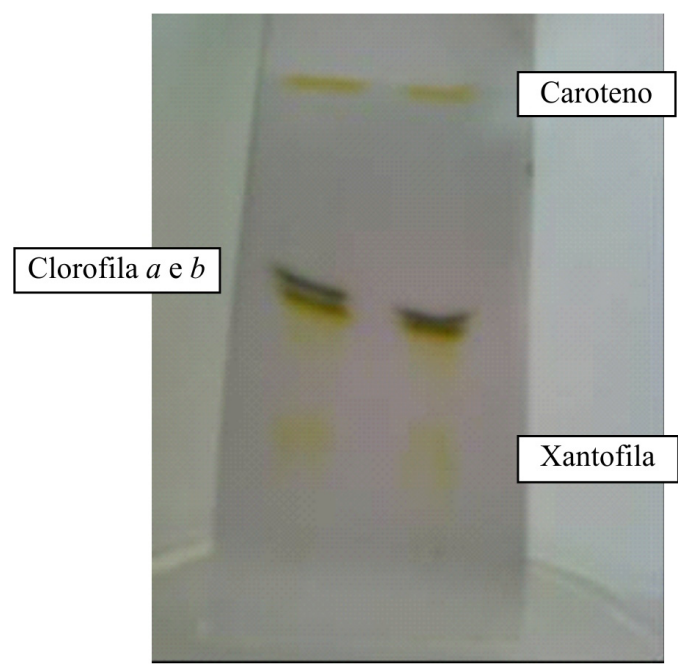

Figura 2. Cromatograma em camada delgada. Eluente: éter de petróleoacetona $(8: 2)$

Após realização do cromatograma partiu-se para o empacotamento da coluna, que foi realizado usando éter de petróleo. A fase estacionária usada no experimento foi sílica obtida da cinza da casca do arroz e a fase móvel (eluente) inicial utilizada foi o éter de petróleo usado na extração.

Por cromatografia em coluna, usando cinza da casca de arroz, previamente tratada, foi possível isolar com pureza aceitável dois pigmentos de cor amarela a $\mathrm{R}_{\mathrm{f}} \approx 0,96$ e 0,32 e um pigmento de cor esverdeada a 0,63 .

O caroteno, cujo $R_{f}$ foi 0,96 , foi o primeiro produto isolado, pois se sabe que os carotenos, como o $\beta$-caroteno, são hidrocarbonetos apolares, nos quais prevalecem interações do tipo forças de London 
(forças de atração entre dipolos temporários). Esses têm pouca afinidade com a fase estacionária e maior afinidade com a fase móvel utilizada nesse experimento, daí ser isolado com éter de petróleo. Esses hidrocarbonetos devem, portanto, ser eluídos com facilidade pela fase móvel e são os que, durante a "corrida" cromatográfica, mais se distanciam do ponto de aplicação da amostra. O $\beta$-caroteno é o mais importante dos precursores da vitamina A e é utilizado como corante na indústria alimentícia

$\mathrm{O}$ segundo produto isolado da coluna foi a clorofila (pigmento verde), cujo $R_{f}$ foi 0,63 . A clorofila é facilmente identificada nas plantas, pois é a responsável pela coloração verde. A clorofila $a$ é a mais abundante no reino vegetal, sendo encontrada, juntamente com a clorofila $b$, numa proporção de $3: 1$, respectivamente. Como as clorofilas $a$ e $b$ apresentam um átomo de magnésio (metal) no centro de uma porfirina, substância que contém quatro unidades ligeiramente modificadas de pirrol, que favorece interações mais fortes com a fase estacionária. Logo, as clorofilas foram isoladas usando-se um sistema mais polar, ou seja, éter de petróleo/etanol na proporção de 9:1.

Finalmente, as xantofilas $\left(\mathrm{R}_{\mathrm{f}}=0,32\right)$, como apresentam grupamento hidroxila e têm moderada afinidade com a fase estacionária utilizada nesse experimento, foram o último produto a ser isolado. Assim, as xantofilas mono-oxigenadas apresentam certa tendência à retenção pela fase estacionária e, durante a "corrida" cromatográfica, distanciam-se moderadamente do ponto de aplicação da amostra. Este produto, por ser o último, foi isolado em um sistema de éter de petróleo e etanol, na proporção de 6:4. A Figura 3 demonstra as etapas de isolamento dos pigmentos.

Convém destacar que os produtos foram identificados pela coloração, por exemplo, $\beta$-carotenos (cor amarela), xantofilas (cor

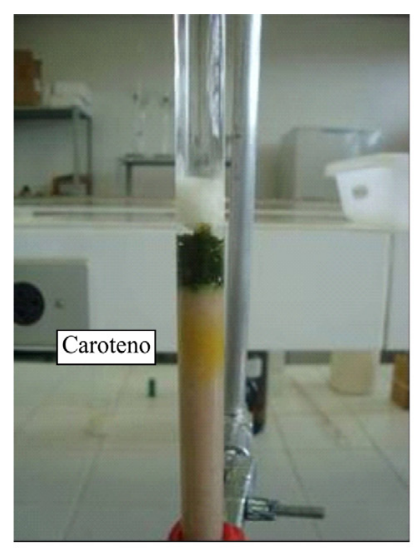

a)

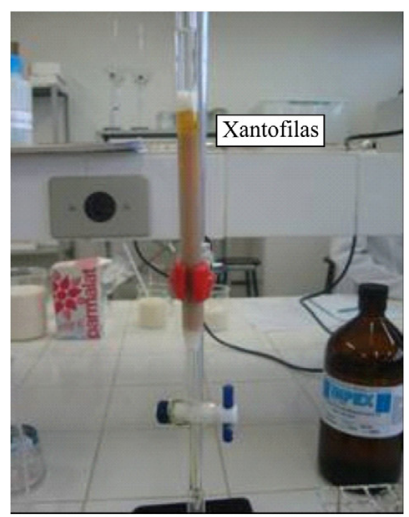

c)

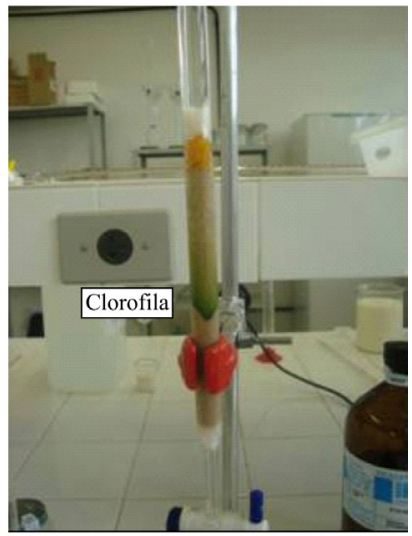

b)

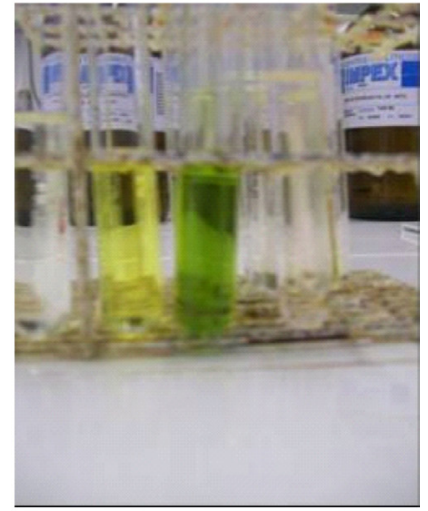

d)
Figura 3. Etapas de isolamento dos pigmentos: a) isolamento do caroteno; $b$ ) isolamento da clorofila; c) isolamento da xantofila; d) pigmentos separados da coluna amarela) e clorofila $a$ (cor verde) e clorofila $b$ (verde-amarelada). Não foi possível neste experimento isolar a clorofila $b$ (verde-amarelada), porque no sistema usado para "corrida" da placa analítica os $\mathrm{R}_{\mathrm{f}}$ eram muito próximos. Os produtos isolados não foram caracterizados, pois já existem relatos na literatura de separação cromatográfica e caracterização dos constituintes do espinafre. ${ }^{14,21}$

\section{CONCLUSÕES}

Este trabalho abordou os resultados de experimentos de cromatografia, realizados em uma aula de química orgânica experimental com 4 h de duração, extração dos pigmentos das folhas de espinafre fresco e, posteriormente, separação cromatográfica. Foi proposta para empacotamento da coluna sílica obtida da cinza do arroz. O procedimento experimental para obtenção da sílica antecedeu as $4 \mathrm{~h}$ planejadas para extração dos pigmentos, realização da cromatografia em camada delgada, empacotamento e realização da separação cromatográfica dos constituintes do espinafre.

Os experimentos de cromatografia em camada delgada indicaram o sistema hexano-etanol (9:1) como o eluente para "corrida" e separação dos produtos. Na separação dos pigmentos em cromatografia em coluna, inicialmente usou-se éter de petróleo para isolar o $\beta$-caroteno, em seguida, o sistema éter de petróleo-etanol (9:1) para clorofila e, finalmente, éter de petróleo-etanol (6:4) para isolamento da xantofila.

$\mathrm{O}$ experimento descrito é facilmente executado em sala de aula ou em laboratório e permite aos estudantes entrarem em contato com vários conceitos envolvidos, desde a extração de compostos de plantas com o auxílio de solventes até a cromatografia do extrato obtido. Alguns conceitos, tais como, solubilidade, polaridade, coeficiente de partição, adsorção e fator de retenção $\left(\mathrm{R}_{\mathrm{f}}\right)$ foram abordados durante a execução do experimento, como também metodologia para obtenção da sílica a partir da cinza da casca do arroz.

\section{REFERÊNCIAS}

1. Etre, L. S.; Pure Appl. Chem. 1993, 65, 81H72.

2. da Silva, L. B.; Alles, I. M.; Morel, A. F.; Dalcol, I. I.; Química Nova na Escola 2006, n. 23, 52.

3. Degani, A. L. G.; Cass, Q. B.; Vieira, P. C.; Química Nova na Escola. 1998, $n^{\circ} .7,21$.

4. Collins, C. H.; Braga, G. L.; Bonato, P. S.; Introdução a Métodos

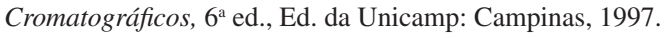

5. Pavia, D. L.; Lampmam, G. M.; Kriz, G. S.; Engel, R. G.; Introduction to Organic Laboratory Techniques: a microscale approach, $3^{\text {rd }}$ ed., Saunders College Publishing: Philadelphia, 1998.

6. Soares, B. G.; Sousa, N. A.; Pires, D. X.; Química Orgânica: teoria e técnicas de preparação, purificação e identificação de compostos orgânicos, Guanabara: Rio de Janeiro, 1988.

7. Roberts, R. M.; Gilbert, J. C.; Rodewald, L. B.; Wingrove, A. S.; Modern Experimental Organic Chemistry, $4^{\text {th }}$ ed., Saunders College Publishing: Philadelphia, 1985.

8. Quach, H. T.; Steeper, R. L.; Griffin, G. W.; J. Chem. Educ. 2004, 81, 385.

9. Chaves, M. H.; Quim. Nova 1997, 20, 560

10. Reynolds, R. C.; O’Dell, C. A.; J. Chem. Educ. 1992, 69, 989.

11. Bessler, K. E.; Neder, A. V. F.; Química em Tubos de Ensaio: uma abordagem para principiantes, Edgard Blücher: São Paulo, 2004.

12. Oliveira, A. R. M.; Simonelli, F.; Marques, F. A.; Química Nova na Escola 1998, nº. 7, 37.

13. Celeghini, R. M. S.; Ferreira, L. H.; Química Nova na Escola 1998, nº. 7, 39 .

14. Fonseca, S. F.; Gonçalves, C. C. S.; Química Nova na Escola 2004, nº. 20,55 . 
15. Okumura, F.; Soares, M. H. F. B.; Cavalheiro, E. T. G.; Quim. Nova 2002, 25, 680 .

16. Ribeiro, N. M.; Nunes, C. R.; Química Nova na Escola 2008, nº. 23, 34.

17. Della, V. P.; Hotza, D.; Junkes, J. A.; Oliveira, A. P. N.; Quim. Nova 2006, 29, 1175.

18. Fonseca, M. R. G.; Tese de Doutorado, Universidade Federal do Rio Grande do Sul, Brasil, 1999.
19. Santos, S.; Dissertação de Mestrado, Universidade Federal de Santa Catarina, Brasil, 1997.

20. Vieira Jr., G. M.; Carvalho, A. A.; Gonzaga, W. A.; Chaves, M. H.; Quim. Nova 2007, 30, 491.

21. Sherma, J.; Fried, B.; J. Planar Chromatogr. 2004, 5, 343. 